\title{
Performance analysis of routing protocols in MANET
}

\author{
Gajanan Madhavrao Walunjkar, Koteswara Rao Anne \\ Computer Science and Engineering, Vel Tech Rangarajan Dr. Sagunthala R\& D, \\ Institute of Science and Technology, India
}

\begin{tabular}{l}
\hline \hline Article Info \\
\hline Article history: \\
Received Jun 2, 2019 \\
Revised Aug 4, 2019 \\
Accepted Aug 18, 2019 \\
\hline
\end{tabular}

Keywords:

AODV

AOMDV

DSDV

DSR

MANET

OLSR

\begin{abstract}
Popularity of Mobile ad hoc network in research is due to their ad hoc nature and effectiveness at the time of disaster management when no infrastructure support is available. Due to the limited transmission range of wireless network interfaces, multiple network hops may be needed for nodes to exchange data across the network. In such a network, each mobile node operates as a router, forwarding packets for other mobile nodes in the network that may not be within the direct reach. Routing protocols developed for wired networks such as the distance vector or link state protocols are inadequate here as they not only assume mostly fixed topology but also have high overheads. This has lead to several routing algorithms specifically targeted for ad hoc networks. In this paper, we include the MANET supported routing protocols and their performance analysis over different performance parameters such as packet delivery ratio, delay, throughput, control overhead and energy etc.
\end{abstract}

Copyright $@ 2020$ Institute of Advanced Engineering and Science. All rights reserved.

Corresponding Author:

Gajanan Madhavrao Walunjkar,

Vel Tech Rangarajan Dr. Sagunthala R\&D,

Institute of Science and Technology, Avadi, Chennai, India.

Email: gwalunjkar@aitpune.edu.in

\section{INTRODUCTION}

Wireless network is one of the types of data communication network that utilizes wireless connections for connecting devices for exchanging information [1,2]. Wireless network technology avoids the expensive method of the installations of cables for the data connection between devices within various locations. Radio networks and Wi-Fi local networks are two of the examples of wireless networks. There exists two main classification of wireless networks; infrastructure and infrastructure less wireless networks. In the former, the data communications are created and maintained through access points or routers. An example of this type of network is cellular networks. The latter type is basically known as Ad hoc networks. In such a network where stations are capable of created by themselves and exchanging information between them in a multi-hop style without the fixed infrastructure. Such an infrastructure less property of the network can be easily adapt in a given location.

The highly dynamic nature of a mobile ad hoc network results in frequent and unpredictable changes of network topology, adding difficulty and complexity to routing among the mobile nodes. The challenges and complexities, coupled with the critical importance of routing protocol in establishing communications among mobile nodes, make routing area the most active research area within the MANET domain [3].

\section{PROPOSED MODEL}

MANET has routable networking environment to process the exchange of information or packet from one node to other node. Different protocols are simulated for measuring the packet drop rate, the overhead introduced by the routing protocol, end-to-end delay of packet, network throughput, 
energy efficiency etc [4]. MANET Routing Protocols are typically subdivided into two main categories: Proactive Routing Protocols [5] and Reactive Routing Protocols [6]. Proactive protocols constantly analyze the network topology and gather information from it by the exchange of information among the various nodes. This means that when any route from a source to a destination is required it is available immediately. Proactive protocols essentially store routing information in one or more tables and hence they are known as table driven routing protocols [7]. Proactive protocols are Destination Sequenced Distance vector (DSDV) [8, 9], Optimum Link State Routing Protocol (OLSR), Wireless Routing Protocols (WRP). Reactive routing protocols also known as on-demand protocols $[10,11]$ mainly minimize traffic overhead in a network. It is based on "query reply" dialog. It is not continuous but when it is needed it creates a procedure for finding one route from source to the destination. Reactive routing protocols are Dynamic Source Routing (DSR), Ad Hoc On Demand Distance Vector (AODV) [12, 13], Ad Hoc On Demand Multipath Distance Vector (AOMDV).

Hybrid Routing Protocols-Hybrid Routing is the combination of Proactive and Reactive protocols. This protocol is used mainly in hierarchical routing. As it is hierarchical, so the high-level nodes consume more power and memory to maintain more information of routing. Zone-Based Hierarchical Link-State Routing Protocol (ZRP) is the example of hybrid protocol.

DSDV is one of the earliest protocols developed for ad hoc networks. The main idea in DSDV [14] is the use of destination sequence numbers to achieve loop freedom without any inter-nodal coordination. DSDV also uses triggered incremental routing updates between periodic full updates to quickly propagate information about route changes. DSDV maintains route entries only when required. Optimized Link State Routing (OLSR) [15] is based on link state routing where the link state information is exchanged among all other nodes in the network. The Dynamic Source Routing Protocol (DSR) [16] is characterized by the use of source routing. That is, the sender knows the complete hop-by-hop route to the destination. These routes are stored in a route cache. Ad Hoc on Demand Distance Vector Routing (AODV) is pure on-demand routing protocol. AODV uses traditional routing tables, one entry per destination [17]. AOMDV is multi path protocol which is basically extension of AODV protocol [18]. AODMV contains multiple route entries in routing tables which efficiently selects another path when required.

In performance comparision, mobility model also plays vital role. Frequently used mobility model is Random Waypoint Mobility Model (RWMM) in which nodes movement are independent towards random destination and with different velocity. To simulate the desired work, network simulator 2.34 is used. NS2 is discrete event simulator, uses C++ and OTcl languages [19, 20]. In desired simulation environment, the MANET nodes use constant bit rate (CBR) traffic sources when they send data to the Internet domain. In the simulation environment, the mobile nodes move according to our selected random waypoint mobility model. We have generated the movement scenario files using the setdest program and traffic is generated using cbrgen utility. The total duration of each simulation run is 200 seconds. Thus for simulation network parameters listed below in Table 1 are used.

Table 1. Simulation Parameters Used for Analysis

\begin{tabular}{cc}
\hline Parameter & Value \\
\hline Number of nodes & 10 to 100 nodes \\
Mobility model & Random Way Point Mobility Model \\
Simulation time & $200 \mathrm{~s}$ \\
Topology Size & $1000 \mathrm{~m} \times 1000 \mathrm{~m}$ \\
Routing protocols analysed & DSDV, DSR, AODV, AOMDV, OLSR \\
Packet size & 512 bytes \\
\hline
\end{tabular}

\section{RESULTS AND DISCUSSION}

The different performance metrics used for analysis of routing protocols for MANET are packet delivery ratio, end to end delay, routing overhead, throughput and energy consumed [21] etc. Packet delivery ratio is the ratio of the number of delivered data packet to the destination. A greater value of the packet delivery ratio means a better performance of the protocol [22-24]. AODV and DSR protocols provides highest packet delivery ratio. It is found that DSDV provides very low packet delivery ratio due to the frequent route failures and its proactive nature. Figure 1 shows a graph of the packet delivery ratio for 50 nodes MANET with random mobility by varying interval. Table 2 specifies packet delivery ratio values for different intervals.

End-to-end delay is the average time taken by a data packet to arrive at the destination [25, 26]. Only the data packets that are successfully delivered to the destinations are counted. A lower value of end-toend delay means a better performance of the protocol. DSDV routing protocol provide very low delivery time 
in less traffic network. AODV is worst in case of delivery time. Figure 2 shows a graph of the delay for 50 nodes MANET with random mobility by varying interval. Table 3 specifies delay values for different intervals.

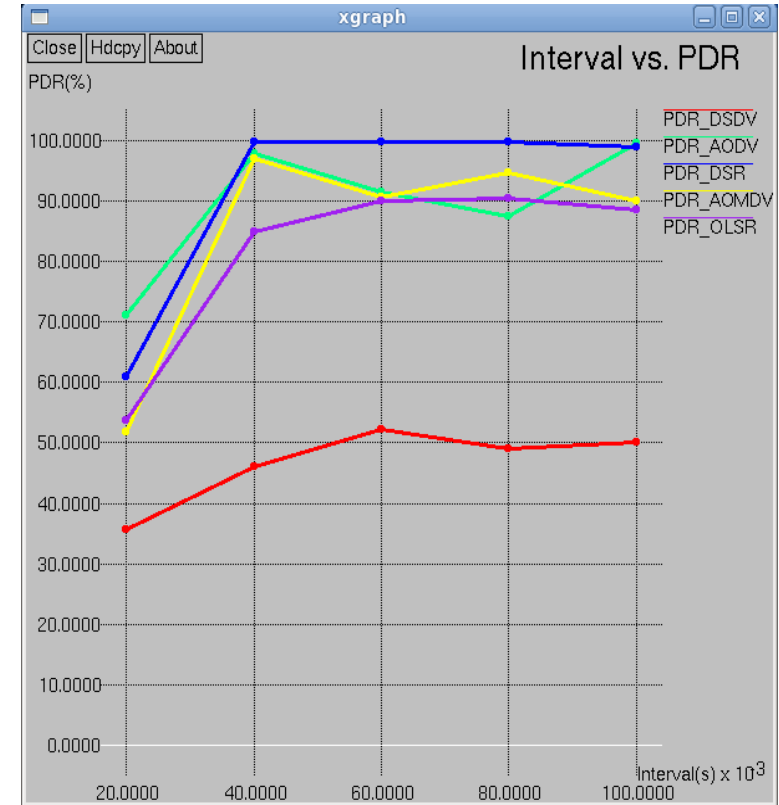

Figure 1. Interval vs. PDR

Table 2. Interval vs. PDR for 50 Nodes Mobile ad Hoc Network with Random Mobility

\begin{tabular}{cccccc}
\hline Interval & 0.02 & 0.04 & 0.06 & 0.08 & 0.10 \\
\hline AODV & 72.36 & 99.75 & 99.12 & 99.07 & 90.00 \\
DSDV & 24.26 & 31.99 & 41.87 & 38.06 & 24.51 \\
DSR & 57.85 & 99.81 & 98.61 & 99.63 & 99.74 \\
OLSR & 53.66 & 84.92 & 90.02 & 90.39 & 88.49 \\
AOMDV & 51.84 & 96.92 & 90.50 & 94.61 & 89.95 \\
\hline
\end{tabular}

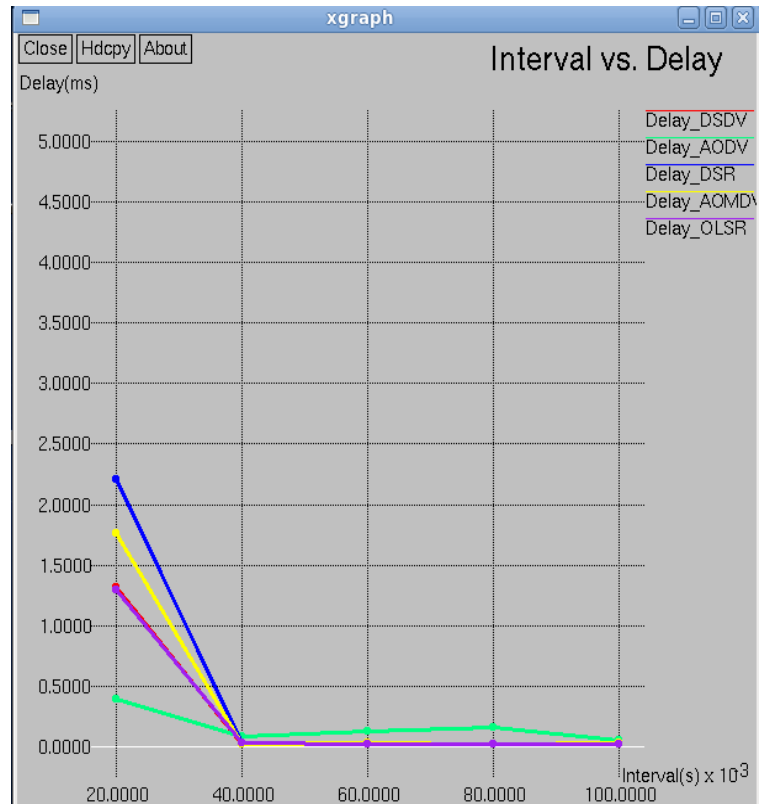

Figure 2. Interval vs. delay

Table 3. Interval vs. Delay for 50 Nodes Mobile ad hoc Network with Random Mobility

\begin{tabular}{cccccc}
\hline Interval & 0.02 & 0.04 & 0.06 & 0.08 & 0.10 \\
\hline AODV & 0.34 & 0.10 & 0.07 & 0.04 & 0.09 \\
DSDV & 1.41 & 0.03 & 0.02 & 0.02 & 0.02 \\
DSR & 2.48 & 0.03 & 0.03 & 0.03 & 0.03 \\
OLSR & 1.29 & 0.03 & 0.02 & 0.02 & 0.02 \\
AOMDV & 1.76 & 0.02 & 0.03 & 0.03 & 0.03 \\
\hline
\end{tabular}

For successful reception of data packets to the destination, control packets are required. Control packets do not carry any useful data; In addition, they consume the bandwidth. Hence, the control overhead should be minimum. DSDV provides largest control overhead due to its proactive nature. AOMDV is multipath routing protocol, which generates large overhead whereas, OLSR provides large control overhead because of link state updates. Figure 3 shows a graph of the control overheads for 50 nodes MANET with random mobility by varying interval. Table 4 specifies packet delivery ratio values for different intervals.

Throughput is the rate at which the data is traversing a link. As we go on increasing the interval, throughput starts decreasing[27]. DSDV provides the lowest throughput while AODV provides the highest throughput. Figure 4 shows a graph of throughput for 50 nodes MANET with random mobility by varying interval. Table 5 specifies throughput values for different intervals.

Nodes in MANET have restricted energy and computing resources. The nodes low in energy level will not be in a position to complete the routing. The routing protocols have to route the packets depending on the MANET constraints such as limited battery power in addition to the optimum path. The limited battery supply to mobile node in MANET, forces the routing protocols to minimize the energy consumption and maximize the network life time. Hence energy efficiency is one of the main problems in a MANET, especially in designing a routing protocol. Figure 5 shows a graph of the average energy consumption for 50 nodes MANET with random mobility by varying interval. Table 6 specifies average energy consumption values for different intervals.

Figure 6 shows a graph of the residual energy for 50 nodes MANET with random mobility by varying interval. Table 4 specifies residual energy values for different intervals. 


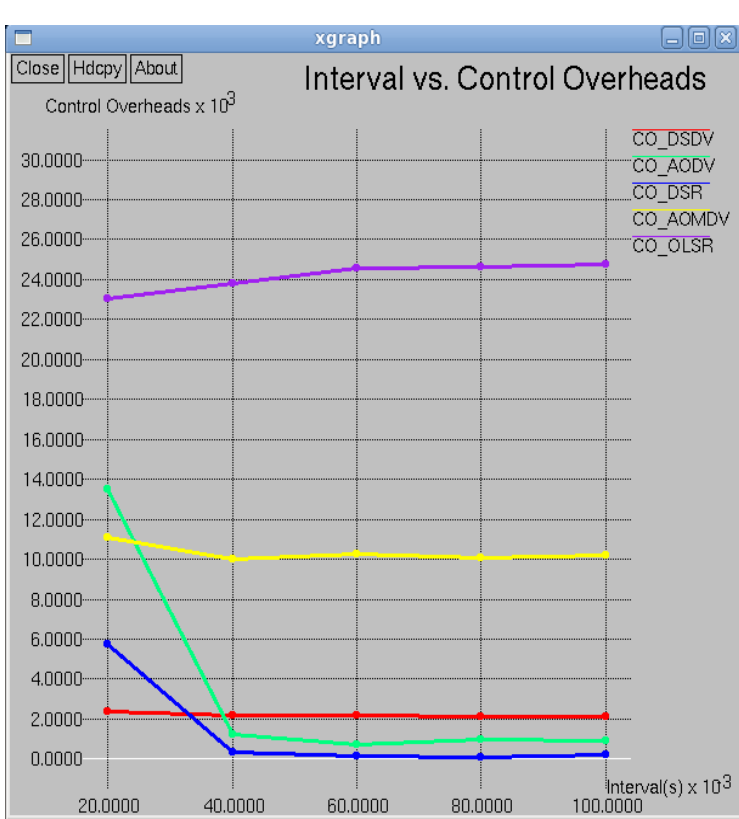

Figure 3. Interval vs. control overheads

Table 4. Interval vs. Control Overheads for 50 Nodes Mobile ad hoc Network with Random

\begin{tabular}{cccccc}
\multicolumn{7}{c}{ Mobility } \\
\hline Interval & 0.02 & 0.04 & 0.06 & 0.08 & 0.10 \\
\hline AODV & 14578 & 1409 & 1147 & 654 & 750 \\
DSDV & 2457 & 2159 & 2170 & 2098 & 2085 \\
DSR & 5333 & 180 & 278 & 92 & 102 \\
OLSR & 23036 & 23828 & 24574 & 24659 & 24763 \\
AOMDV & 11093 & 10036 & 10238 & 10104 & 10195 \\
\hline
\end{tabular}

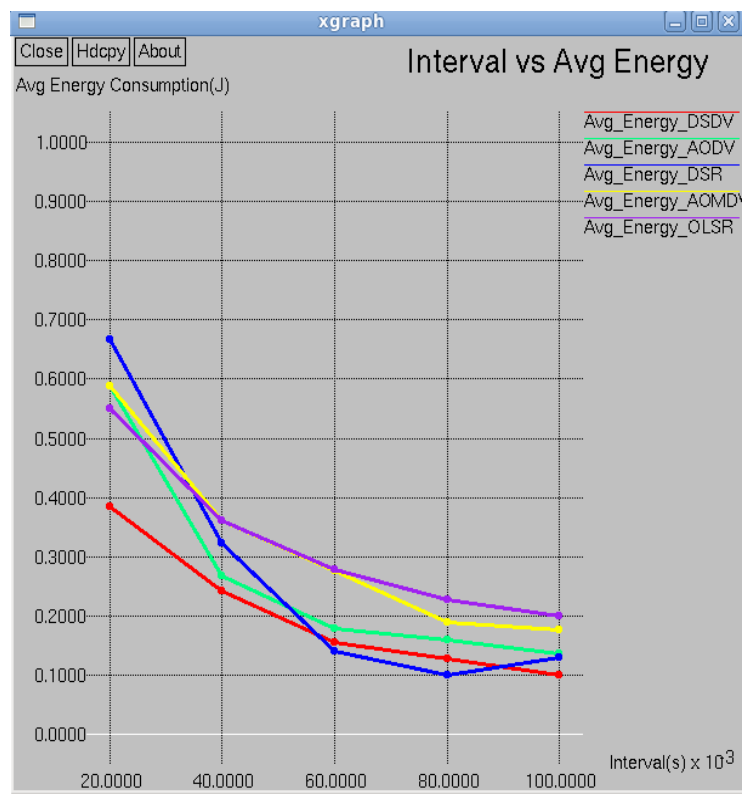

Figure 5. Interval vs. Avg. energy

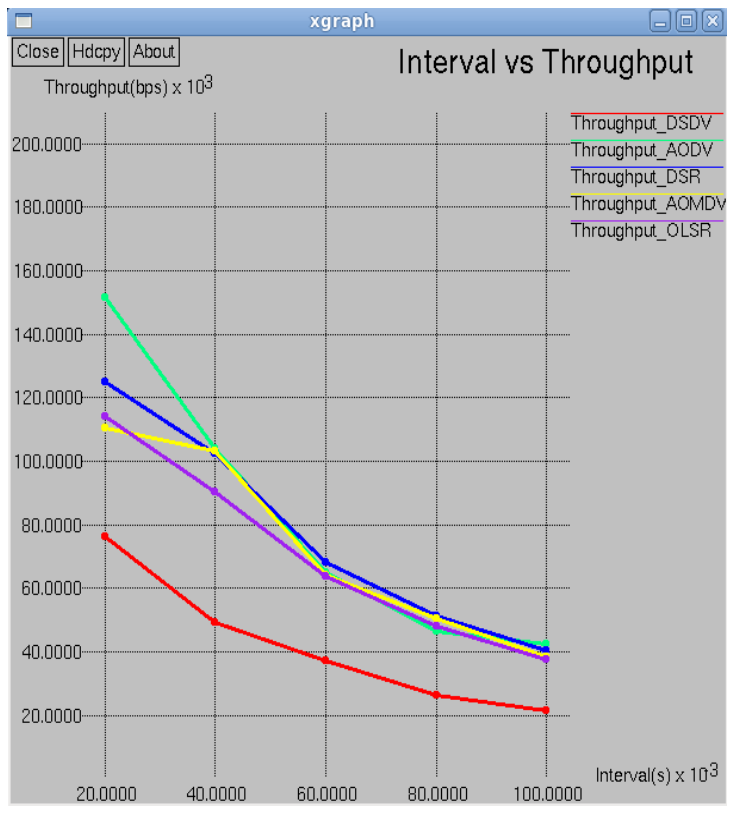

Figure 4. Interval vs. throughput

Table 5. Interval vs. Throughput for 50 Nodes Mobile ad hoc Network with Random Mobility

\begin{tabular}{cccccc}
\hline Interval & 0.02 & 0.04 & 0.06 & 0.08 & 0.10 \\
\hline AODV & 154001 & 101909 & 70334 & 52729 & 38325 \\
DSDV & 51633 & 34052 & 29713 & 20257 & 10437 \\
DSR & 118726 & 102244 & 67347 & 51043 & 40890 \\
OLSR & 114218 & 90381 & 63874 & 48108 & 37683 \\
AOMDV & 110346 & 103149 & 64216 & 50355 & 38304 \\
\hline
\end{tabular}

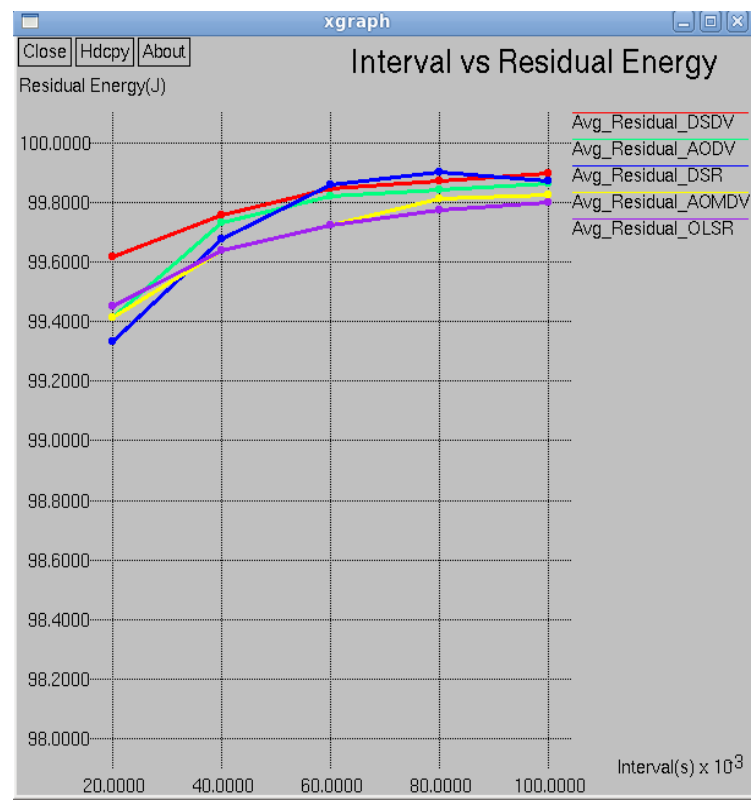

Figure 6. Interval vs. residual energy 
Table 6. Interval vs. Avg. Energy for 50 Nodes Mobile ad hoc Network with Random Mobility

\begin{tabular}{cccccc}
\hline Interval & 0.02 & 0.04 & 0.06 & 0.08 & 0.10 \\
\hline AODV & 0.590 & 0.250 & 0.221 & 0.118 & 0.128 \\
DSDV & 0.362 & 0.198 & 0.144 & 0.112 & 0.090 \\
DSR & 0.728 & 0.282 & 0.263 & 0.171 & 0.122 \\
OLSR & 0.550 & 0.361 & 0.278 & 0.226 & 0.200 \\
AOMDV & 0.588 & 0.361 & 0.276 & 0.190 & 0.176 \\
\hline
\end{tabular}

Table 7. Interval vs. Residual Energy for 50 Nodes Mobile ad hoc Network with Random Mobility

\begin{tabular}{cccccc}
\hline Interval & 0.02 & 0.04 & 0.06 & 0.08 & 0.10 \\
\hline AODV & 99.40 & 99.74 & 99.77 & 99.88 & 99.87 \\
DSDV & 99.63 & 99.80 & 99.85 & 99.88 & 99.90 \\
DSR & 99.27 & 99.71 & 99.73 & 99.82 & 99.87 \\
OLSR & 99.44 & 99.63 & 99.72 & 99.77 & 99.79 \\
AOMDV & 99.41 & 99.63 & 99.72 & 99.81 & 99.82 \\
\hline
\end{tabular}

\section{CONCLUSION}

In this paper, performance analysis of existing routing protocols such as DSDV, OLSR, AODV, AOMDV and DSR is implemented. Various performance metrics such as packet delivery ratio, delay, throughput, control overhead and energy are used. The results obtained from analysis of various proactive and on-demand routing protocols shows, for low loads and low mobility, proactive protocols DSDV gives better results. End-to-end delay is less in DSDV protocols. Packet delivery ratio is highest in case of AODV and DSR Protocols. For high traffic, AODV and DSR protocols are more suitable as they generate less control overhead due to their reactive nature. AODV, AOMDV and DSR protocols provides high throughput while DSDV protocol provides less throughput irrespective of the traffic present on the network. Average energy consumption is less in DSDV protocols as compared with AODV and DSR. Thus DSDV protocol minimizes the energy consumption and maximizes the network life time.

\section{REFERENCES}

[1] Y. Zhang and Y. Shi, “Tactical Wireless Network Visualization: Requirements and Representations,” 2018, IEEE Third International Conference on Data Science in Cyberspace (DSC), Guangzhou, China, pp. 740-743, 2018.

[2] Wan Aida Nadia Wan Abdullah et al, "Impact of Clustering in AODV Routing Protocol for Wireless Body Area Network in Remote Health Monitoring System", Indonesian Journal of Electrical Engineering and Computer Science (IJEECS) Vol. 13, No. 2, pp. 689-695, Feb 2019.

[3] P. Bellavista, G. Cardone, A. Corradi and L. Foschini, "Convergence of MANET and WSN in IoT Urban Scenarios," in IEEE Sensors Journal, vol. 13, no. 10, pp. 3558-3567, Oct 2013.

[4] W. A. Hussein, B. M. Ali, M. F. A. Rasid and F. Hashim, "Design and Performance Analysis of High ReliabilityOptimal Routing Protocol for Mobile Wireless Multimedia Sensor Networks," 2017 IEEE 13th Malaysia International Conference on Communications (MICC), Johor Bahru, pp. 136-140, 2017.

[5] T. T. Son, H. Le Minh, G. Sexton and N. Aslam, "Self-Adaptive Proactive Routing Scheme for Mobile Ad-Hoc Networks," in IET Networks, vol. 4, no. 2, pp. 128-136, 32015.

[6] Rahul Desai, B P Patil, “Analysis of Reinforcement Based Adaptive Routing in MANET”, Indonesian Journal of Electrical Engineering and Computer Science (IJEECS) Vol. 2, No. 3, 2016, pp. 684-694, 2016.

[7] Justin Sophia I, N. Rama," Improving the Proactive Routing Protocol using Depth First Iterative Deepening Spanning Tree in Mobile Ad Hoc Network", International Journal of Electrical and Computer Engineering (IJECE), Vol 7, No 1: February 2017

[8] C. E. Perkins and P. Bhagwat, "Highly dynamic Destination-Sequenced Distance-Vector routing (DSDV) for Mobile Computers," Proc. Conf. Communication. Architectures, Protocols and Applications, 1994, pp. 234-244.

[9] S. Murthy and J. J. Garcia-Luna-Aceves, "An Efficient Routing Protocol for Wireless Networks," ACM J. Mobile Networks and Applications, special issue on Routing in Mobile Communication Networks, vol. 1, no. 2, 1996, pp. $183-197$.

[10] M. Imran and M. A. Qadeer, "Evaluation Study of Performance Comparison of Topology Based Routing Protocol, AODV and DSDV in MANET," 2016 International Conference on Micro-Electronics and Telecommunication Engineering, Ghaziabad, 2016, pp. 207-211.

[11] N. Meghanathan, "A Location Prediction-Based Reactive Routing Protocol to Minimize the Number of Route Discoveries and Hop Count per Path in Mobile Ad Hoc Networks," in The Computer Journal, vol. 52, no. 4, pp. 461-482, July 2009.

[12] AL-Gabri Malek, Chunlin LI, Layuan Li , "Improving ZigBee AODV Mesh Routing Algorithm Topology and Simulation Analysis", TELKOMNIKA Indonesian Journal of Electrical Engineering Vol.12, No.2, February 2014, pp. $1528 \sim 1535$

[13] Shalini Singh, Rajeev Tripathi, "Performance Analysis of Extended AODV with IEEE802.11e HCCA to support QoS in Hybrid Network", Indonesian Journal of Electrical Engineering and Computer Science (IJEECS), Vol 12, No 9: September 2014

[14] Y. Fengjie, Y. Hui and Z. Ying, "Research on DSDV Routing Protocol Based on Wireless Mesh Network," 2018 Chinese Control And Decision Conference (CCDC), Shenyang, China, pp. 4292-4297. 2018.

[15] Zhihao Ding, Pinyi Ren, Qinghe Du, "Mobility Based Routing Protocol with MAC Collision Improvement in Vehicular Ad Hoc Networks," Communications Workshops (ICC Workshops) 2018 IEEE International Conference on, 2018. 
[16] Yujun Zhang, Guiling Wang, Qi Hu, Zhongcheng Li, Jie Tian, "Design and Performance Study Of A TopologyHiding Multipath Routing Protocol for Mobile Ad Hoc Networks", INFOCOM 2012 Proceedings IEEE, pp. 10-18, 2012.

[17] A. Garcia-Santiago, J. Castaneda-Camacho, J. F. Guerrero-Castellanos and G. Mino-Aguilar, "Evaluation of AODV and DSDV Routing Protocols for a FANET: Further Results Towards Robotic Vehicle Networks, " 2018 IEEE 9th Latin American Symposium on Circuits \& Systems (LASCAS), Puerto Vallarta, Mexico, pp. 1-4. 2018.

[18] A. K. Yogi and J. Surana, "An Implementation of Modified AOMDV Routing Protocol in Different Wireless Networks, " 2016 International Conference on ICT in Business Industry \& Government (ICTBIG), Indore, 2016, pp. 1-5. 2016.

[19] Manijeh Keshtgary, Negar Rikhtegar, "Performance evaluation of routing protocols for wireless sensor networks in forest fire detection application," Information and Knowledge Technology (IKT) 2013 5th Conference on, pp. 248-251, 2013

[20] Rahul Desai, B P Patil, "Routing protocols for Mobile Ad Hoc Network - A Survey and Analysis", Indonesian Journal of Electrical Engineering and Computer Science (IJEECS) Vol. 7, No. 3, 2017.

[21] S. K. Srivastava, R. D. Raut and P. T. Karule, "Analyzing the Performance of Routing Protocols Based on Evaluation of Different Parameters in MANETs," 2015 International Conference on Communication Networks (ICCN), Gwalior, pp. 258-261. 2015.

[22] U. Draz, T. Ali, S. Yasin and A. Shaf, "Evaluation Based Analysis of Packet Delivery Ratio for AODV and DSR Under UDP and TCP Environment," 2018 International Conference on Computing, Mathematics and Engineering Technologies (iCoMET), Sukkur, pp. 1-7, 2018.

[23] Wan Aida Nadia Wan Abdullah et al, "Corrupted Packets Discarding Mechanism to Alleviate Congestion in Wireless Body Area Network", Indonesian Journal of Electrical Engineering and Computer Science (IJEECS), Vol. 14, No. 2, pp. 581-587. May 2019.

[24] Nur Aishah Bt. Zainal, Mohamed Hadi Habaebi, Israth Jahan Chowdhury, Md Rafiqul Islam, Jamal I. Daoud, "Gateway Sink Placement for Sensor Node Grid Distribution in Lora Smart City Networks", Indonesian Journal of Electrical Engineering and Computer Science (IJEECS), Vol 14, No 2, pp. 834-842, May 2019.

[25] Nabeena Ameen, Najumnissa Jamal, L. Arun Raj, "Comparative Analysis of Energy Based Optimized Dynamic Source Multipath Routing Protocol in WSNs", Indonesian Journal of Electrical Engineering and Computer Science (IJEECS), Vol. 16, No. 1, pp. 441-455, Oct 2019.

[26] Noor Alleema, D. Siva Kumar, "Cooperative and fresher encounter algorithm for reducing delay in MANET, Indonesian Journal of Electrical Engineering and Computer Science (IJEECS) Vol. 14, No. 3, June 2019, pp. 1258 1265

[27] Anand R, Jitendranath Mungara, "Wireless Environment Aware Adaptive Scheduling Technique for Cellular Networks, Indonesian Journal of Electrical Engineering and Computer Science (IJEECS) Vol. 11, No. 1, July 2018, pp. 318 332 